$16^{\text {th }}$ International Congress of Metrology, 16002 (2013)

DOI: $10.1051 /$ metrology/201316002

(C) Owned by the authors, published by EDP Sciences, 2013

\title{
Estimation of uncertainty to the homogeneity study in the certification of a candidate certified reference material in fish matrix
}

\author{
João Cristiano Ulrich ${ }^{1, \mathrm{a}}$ and Jorge Eduardo de Souza Sarkis ${ }^{1}$ \\ ${ }^{1}$ Instituto de Pesquisas Energéticas e Nucleares - Ipen/CNEN-SP, Brazil
}

\begin{abstract}
A homogeneity study in the preparation of a fish candidate certified reference material is reported. In the present study, homogeneity was examined by flow injection analysis cold vapour atomic absorption spectrometry technique (FIA-CV-AAS). Total mercury and methylmercury were studied in this study. Univariate analysis of variance (ANOVA) was performed for all analytes. The results were evaluated using an F-test, which demonstrated no significant difference for the between-bottle results. It is indicative that this material is homogeneous. The results of the between-bottle homogeneity study provide for the evaluation of one of the uncertainty components in the certification process.
\end{abstract}

\section{Introduction}

Seafood is an important source of protein and income for people around the world. However, harmful substances including toxic elements released by humans activities have contaminated the marine environment.

Mercury $(\mathrm{Hg})$ is a pollutant with extreme toxicity and one of the most toxic elements [1]. It is well know that methylmercury is a dominant organic mercury specie in fish $(85-99 \%$ of total $\mathrm{Hg}$ levels are present in aquatic organisms) [2].

The determination of $\mathrm{Hg}$ and $\mathrm{MeHg}$ in seafood samples has been done using many tecniques [3-6] and the quality of the results can be guarantee by the use of certified reference materials (CRMs).

CRMs are widely used for check measurement process, precision and accuracy verification [7].

Homogeneity study is one important part of the certification process of the CRMs. The results of the between-bottle homogeneity study provide for the evaluation of one of the uncertainty components in the certification process. A homogeneity study is not intended to show that there are differences from the ideal equal distribution of some properties, but to show that inhomogeneities might be of importance for the analytical method used. In the present study, homogeneity was examined by flow injection analysis cold vapour atomic absorption spectrometry technique (FIA-CV-AAS), which is accredited method by ISO 17025 standard [8] in our laboratory. Total mercury and methylmercury were studied in homogeneity study.

A subsampling problem associated with many reference materials is that only a small test portion is drawn from the sample to carry out the measurement process. Obviously, this test portion must be representative of the sample, otherwise the certified value is still not applicable. Then, the influence of the sample mass on the homogeneity of the material was also evaluated.

The results were then evaluated statistically.

\section{Experimental}

\subsection{Homogeneity study layout}

A $1.2 \mathrm{~kg}$ amount of material was processed, which was distributed in 80 bottles, each containing $15 \mathrm{~g}$. For the between-bottle homogeneity study were selected 10 bottles (bottle numbers 2, 9, 14, 26, 31, 36, 50, 55, 63 e 78). For the within bottle homogeneity study, bottle number 10 was selected.

\subsection{Sample and elemental standard preparation}

For the between-bottle homogeneity study, three subsamples, for each analyte, were taken from each bottle. For total $\mathrm{Hg}$ and $\mathrm{MeHg}$ determination, subsamples of approximately $400 \mathrm{mg}$ and $500 \mathrm{mg}$ were used, respectively. The samples were digested for total mercury determination by an open flask procedure developed earlier [9] and for $\mathrm{MeHg}$ determination, organic and inorganic $\mathrm{Hg}$ were separated and then analysed [10]. For the within bottle homogeneity study, seven subsamples of 200, 300, 400,500, 600, 700 and $800 \mathrm{mg}$ were used from the same bottle. 
The total $\mathrm{Hg}$ and $\mathrm{MeHg}$ content of the aliquot sample were calculated against the mercury standard curves. For this purpose were prepared six mercury standards solutions. Those solutions were obtained of the dilution of a standard solution of $1000.14 \mu \mathrm{g} \mathrm{mL}-1$ prepared from the mercury oxide.

\subsection{Instrumentation and determinations}

All the determinations were carried out using an atomic absorption spectrophotometer (SpectrAA220-FS, Varian Australia Pty Ltd.), at $253.7 \mathrm{~nm}$. This spectrophotometer was coupled to a typical flow analysis injection (FIA) manifold. Before all analyses, the instrument was checked according to the instrument manufacturer's instructions.

\section{Results and discussion}

Statistical analysis was carried out and the uncertainties of homogeneity for both analytes were calculated. Normally, a one-way analysis of variance (ANOVA) approach [11] is used to assess the between bottle homogeneity as well as the within bottle homogeneity, but for $\mathrm{MeHg}$, another statistical method was used to confirm the homogeneity.

In according with the ISO Guide 35 [12], the calculations were performed and the tables 1 and 2 shows the values for the between bottle homogeneity of each analyte.

Table 1. Analysis of variance (ANOVA) table for total $\mathrm{Hg}$ in fish

\begin{tabular}{|l|c|c|c|c|c|c|}
\hline $\begin{array}{c}\text { Source of } \\
\text { variation }\end{array}$ & $\mathrm{SS}$ & $\mathrm{d} f$ & $\mathrm{MS}$ & $\mathrm{F}$ & $\mathrm{P}$-value & $\mathrm{F}_{\text {crit }}$ \\
\hline $\begin{array}{l}\text { Between } \\
\text { groups }\end{array}$ & 0.00639 & 9 & 0.000711 & 0.65 & 0.74 & 2.39 \\
\hline $\begin{array}{l}\text { Within } \\
\text { groups }\end{array}$ & 0.02183 & 20 & 0.001092 & & & \\
\hline Total & 0.02822 & 29 & & & & \\
\hline
\end{tabular}

Where SS provides the sums of squares, $\mathrm{d} f$ the associated degrees of freedom, MS the mean squares, and the F-test indicated that the result of the homogeneity is insignificant $\left(\mathrm{F}<\mathrm{F}_{\text {crit }}\right.$, the critical value of $\mathrm{F}$ for $\alpha=5 \%$ ). The $\mathrm{P}$-value gives the level for which the observed $F$ equals $F$ crit.

Table 2. Analysis of variance (ANOVA) table for $\mathrm{MeHg}$ in fish

\begin{tabular}{|l|c|c|c|c|c|c|}
\hline $\begin{array}{c}\text { Source of } \\
\text { variation }\end{array}$ & $\mathrm{SS}$ & $\mathrm{d} f$ & $\mathrm{MS}$ & $\mathrm{F}$ & P-value & F crit \\
\hline $\begin{array}{l}\text { Between } \\
\text { groups }\end{array}$ & 0.09502 & 9 & 0.01055 & 2.72 & 0.029 & 2.39 \\
\hline $\begin{array}{l}\text { Within } \\
\text { groups }\end{array}$ & 0.07739 & 20 & 0.00387 & & & \\
\hline Total & 0.17241 & 29 & & & & \\
\hline
\end{tabular}

The table 2 shows that for $\mathrm{MeHg}$ determination the F-test indicated that the result of the homogeneity is significant $\left(F>F_{\text {crit }}\right.$, the critical value of $F$ for $\left.\alpha=5 \%\right)$. The homogeneity, for $\mathrm{MeHg}$, is not confirmed. Checking the data obtained from the calculation of variance for these measurement values, it is observed that one of the assumptions of the ANOVA was not confirmed because the variances are different. The difference in the values variance may be from the analytical method used in the measurements (FIA-CVAAS), performed in different days, shows the variations in the response signals of both the calibration curve as the signals of the samples.

Thus, a most suitable test for assessing the homogeneity, for $\mathrm{MeHg}$, proposed by Fearn and Thompson [13], called "sufficient homogeneity" was used. This statistical method is specified in the Harmonised Protocol Procedure [14]. This test provides estimates of the analytical variance $\sigma^{2}$ an and the between-sample variance or sampling variance, $\sigma_{\text {sam }}^{2}$, but is impose a limit on the true sampling variance.

As recommended in the instructions [13], were analyzed in duplicate portions of 10 bottles under repeatibility conditions and the results of evaluation of the data is shown in table 3.

The items presented after the table are shown the equations used for the calculations and their results. In item (a), the analytical variance $\left(\mathrm{s}^{2}\right.$ an $)$ is obtained by dividing the sum of squares of differences $\left(D^{2}\right)$ by $2 \mathrm{~m}$, where $\mathrm{m}$ is the number of bottles. In (b) the analytical precision as standard deviation. In (c) is obtained the value of estimative of the between-sample variance $\left(\mathrm{s}_{\text {sam }}^{2}\right)$. The value for acceptable between-sample variance $\left(\sigma^{2}\right.$ all $)$, calculated in $(d)$, is obtained after the value of the target standard deviation $\left(\sigma_{p}\right)$ calculated by the Horwitz function $[14,15]$. The critical value for the homogeneity test (homogeneity study), called "c", obtained in (e) by multiplication of specific factors [13] by the values of $\left(\sigma^{2}\right.$ all $)$ and $\left(s_{\text {an }}^{2}\right)$, and these values are then summed. If $\mathrm{s}_{\mathrm{sam}}^{2}>\mathrm{c}$, there is evidence that the sampling standard deviation in the population of samples exceeds the allowable fraction of the target standard deviation, and the test for homogeneity failed. If $\mathrm{s}_{\text {sam }}^{2}<\mathrm{c}$, there is no evidence, and the test for homogeneity was accepted.

Table 3. Homogeneity test between-bottles, applied in $\mathrm{MeHg}$ data

\begin{tabular}{|c|c|c|c|c|c|}
\hline $\begin{array}{c}\text { Bottle } \\
\text { N. }\end{array}$ & $\begin{array}{c}\text { Result } \\
\text { (a) }\end{array}$ & $\begin{array}{c}\text { Result } \\
(\mathrm{b})\end{array}$ & $\mathrm{D}=\mathrm{a}-\mathrm{b}$ & $\begin{array}{c}\mathrm{S}= \\
\mathrm{a}+\mathrm{b}\end{array}$ & $\begin{array}{c}\mathrm{D}^{2}= \\
(\mathrm{a}-\mathrm{b})^{2}\end{array}$ \\
\hline 2 & 0.296 & 0.295 & 0.001 & 0.591 & 0.000001 \\
\hline 9 & 0.195 & 0.241 & -0.046 & 0.436 & 0.002116 \\
\hline 14 & 0.291 & 0.333 & -0.042 & 0.624 & 0.001764 \\
\hline 26 & 0.245 & 0.255 & -0.010 & 0.500 & 0.000100 \\
\hline 31 & 0.379 & 0.226 & 0.153 & 0.605 & 0.023409 \\
\hline 36 & 0.382 & 0.332 & 0.050 & 0.714 & 0.002500 \\
\hline 50 & 0.328 & 0.329 & -0.001 & 0.657 & 0.000001 \\
\hline 55 & 0.217 & 0.237 & -0.020 & 0.454 & 0.000400 \\
\hline
\end{tabular}




\begin{tabular}{|l|l|l|l|l|l|}
\hline 63 & 0.208 & 0.215 & -0.007 & 0.423 & 0.000049 \\
\hline 78 & 0.243 & 0.224 & 0.019 & 0.467 & 0.000361 \\
\hline \multicolumn{6}{c|}{ Somatória $=0.030701$} \\
\hline
\end{tabular}

(a) $\mathrm{s}_{\text {an }}^{2}=\mathrm{D}^{2} / 2 \mathrm{~m}=0.030701 /(210)=0.001535 \mu \mathrm{g} \mathrm{g}^{-1}$ (analytical variance)

(b) $\mathrm{s}_{\mathrm{an}}=\sqrt{\mathrm{s}_{\mathrm{an}}^{2}}=\sqrt{0.001535}=0.039179 \mu \mathrm{g} \mathrm{g}^{-1}$

(c) $\mathrm{s}_{\text {sam }}^{2}=\left(\mathrm{s}_{\mathrm{S}}^{2} / 2-\mathrm{s}_{\text {an }}^{2}\right) / 2=(0.010686 / 2-0.001535) / 2$ $=0.001904$

(d) $\sigma_{1}^{2}$ all $=\left(0.3 \sigma_{\mathrm{p}}\right)^{2}=(0.30 .05326)^{2}=0.000255 \mu \mathrm{g} \mathrm{kg}-$

$\sigma_{\mathrm{p}}$ (obtained by Horwitz function) $=0.02 \mathrm{c}^{0.8495}=$ $0.02\left(0.27410^{-6}\right)^{0.8495} / 10^{-6}=0.05326 \mu \mathrm{g} \mathrm{g}^{-1}$ (where "c" is average concentration of $\mathrm{MeHg}$ expressed as mass fraction).

(e) $\mathrm{c}=\mathrm{F}_{1} \sigma_{\text {all }}^{2}+\mathrm{F}_{2} \mathrm{~S}_{\text {an }}^{2}=1.880 .0002553+1.01$ $0.001535=0.002030$.

Using the criterion, $\mathrm{s}_{\mathrm{sam}}^{2}=0.001904<\mathrm{c}=0.002030$, the test is accepted and the material is sufficient homogeneous.

\subsection{Within bottle homogeneity study}

For the estimation of the minimum sample intake, total $\mathrm{Hg}$ was determined in all subsamples by FIA-CV-AAS. The standard deviation values are compared in the mass range studied. Figure 1 presents the results.

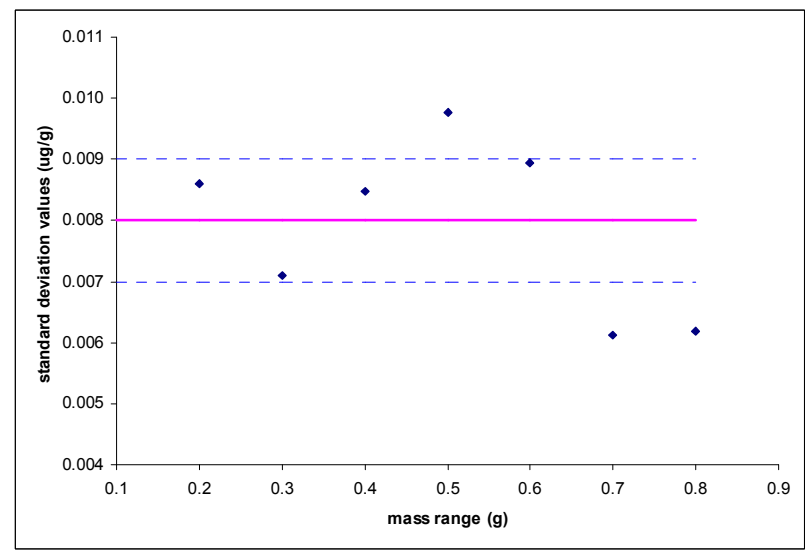

Figure 1. Standard deviation values as a function of sample mass in the within bottle.

The results obtained showed that mass range throughout the study proved satisfactory standard deviations, indicating that for the analytical methodology used it is possible to use a minimum mass of $0.2 \mathrm{~g}$.

\subsection{Homogeneity contribution to CRM uncertainty}

The estimative of standard uncertainty due to betweenbottle homogeneity $\left(\mathrm{u}_{\mathrm{bb}}\right)$ was calculated by equation 1 $[16,12]$ :

$$
u_{b b}=\sqrt{\frac{M S_{\text {within }}}{n}} \sqrt[4]{\frac{2}{v_{\text {MSwithin }}}}
$$

where $\mathrm{MS}_{\text {within }}$ represents the mean squares among groups. In case of "sufficient homogeneity" [13], $\mathrm{MS}_{\text {within }}$ is the same estimative of the analytical variance $\left(\mathrm{s}^{2}{ }_{\text {an }}\right), \mathrm{n}=$ number of replicates per unit and $v_{\text {Mswithin }}$ is the degrees of freedom of $\mathrm{MS}_{\text {within }}$.

For total Hg:

$$
u_{b b}=\sqrt{\frac{0.001092}{9}} \sqrt[4]{\frac{2}{20}}=0.006194 \mu \mathrm{g} \mathrm{g}^{-1},
$$

For MeHg:

$$
u_{b b}=\sqrt{\frac{0.00153}{6}} \sqrt[4]{\frac{2}{10}}=0.01067 \mu \mathrm{g} \mathrm{g}^{-1} .
$$

This value of $\mathrm{u}_{\mathrm{bb}}$ will be included in the uncertainty budget, for each analyte, as an estimate for the uncertainty of between-bottle homogeneity.

\section{Conclusions}

The homogeneity study in the material for the total $\mathrm{Hg}$ and $\mathrm{MeHg}$ was realized. The homogeneity test should be designed to identify the variability due to possible inhomogeneity of the material packed, to be made available to the user.

The statistical tool proposed by Fearn and Thompson [13], is suitable when some of the assumptions of ANOVA not be confirmed and thus proved the homogeneity for the analyte $\mathrm{MeHg}$.

The study showed that the minimum mass to mass range studied, standard deviations were practically the same indicating repeatibility for the smallest portion and the largest portion, analyzed by FIA-CV-AAS technique. Note that, according to the ISO Guide 33 standard, the user should be aware that use of a portion of the material that does not meet or exceed the specification can significantly increase the contribution of the inhomogeneity of the CRM for the uncertainty property certified until the point at which the statistical parameters of cerfication are not longer valid.

The contribution of standard uncertainty of homogeneity study have important implications for the final uncertainty of the CRM, because besides mandatory term and indicates the variability of the batch prepared. 


\section{References}

1. F.A. Azevedo, Toxicologia do mercúrio, São Paulo: Rima, Intertox, ch. 5, pp. 95-114 (2003)

2. Agency for Toxic Substances and Disease Registry, Potential for human exposure (chapter 5), in: Toxicological profile for mercury update, US

Department of Health and Human Services, (1999) http://www.atsdr.cdc.gov/toxprofiles/tp46.pdf

3. F.A. Duarte, C.A. Bizzi, F.G. Antes, V.L. Dressler, E.M.M. Flores, Spectrochimica Acta Part B, 64, 513-519 (2009)

4. M.S. Gustin, L. Saito, M. Peacock, Science of the Total Environment, 347, 282-294 (2005)

5. M. Kan, S.N. Willie, C. Scriver, R.R. Sturgeon, Talanta, 68, 1259-1263 (2006)

6. I. Serafimovski, I. Karadjova, T. Stafilov, J. Cvetkovi'c, Microchemical Journal, 89, 42-47 (2008)

7. Associação Brasileira de Normas Técnicas ABNT, ABNT ISO Guia 33 (2002)

8. Associação Brasileira de Normas Técnicas ABNT, ABNT NBR ISO/IEC 17025 (2005)

9. J.S. Azevedo, J.E.S. Sarkis, T.A. Oliveira, J.C. Ulrich, Brazilian Journal of Oceanography, 60, 2, 209217 (2012)

10. J.C. Ulrich, H.M. Shihomatsu, M.A. Hortellani, J.E.S. Sarkis, XVIII IMEKO World Congress, Rio de Janeiro - Brazil, 17-22 september, (2006) http://www.imeko.org/publications/wc-2006/PWC2006-TC8-019u.pdf

11. A.M.H. van der Veen, T. Linsinger, J. Pauwels, Accredit Qual Assur, 6, 26-30 (2001)

12. ISO Guide 35 (2006) Reference materialsgeneral and statistical principles for certification. International Organization for Standardization (ISO), Geneva

13. T. Fearn, M. Thompson, Analyst, 126, 14141417 (2001)

14. M. Thompson, S.L.R. Ellison, R. Wood, Pure Appl. Chem., 78, 1, 145-196 (2006)

15. R Albert, W. Horwitz, Anal. Chem., 69, 789-790 (1997)

16. T.P.J. Linsinger, J. Pauwels, A.M.H. van der Veen, H. Schimmel, A. Lamberty, Accred. Qual. Assur., 6, 20-25 (2001) 